\title{
Prophylactic impact of Egyptian propolis on rat liver exposed to aluminum silicate toxicity: biochemical and histopathological studies
}

\author{
${ }^{1}$ Zoology Department, Faculty of Science, Port Said University, Port Said, Egypt \\ ${ }^{2}$ Zoology Department, Faculty of Science, Damietta University, Damietta, Egypt \\ ${ }^{3}$ Zoology Department, Faculty of Science, Mansoura University, Mansoura, Egypt
}

Ali H. Abu-Almaaty' ${ }^{1}$ Yasmin M. Abd El-Aziz ${ }^{1}$, Nahed A. Omar², Ahmed M. Abdeen ${ }^{3}$

Correspondence Author: Ali Hussein Abu-Almaaty, Ph. D. Biotechnology Program, Department of Zoology, Faculty of Science, Port Said University, Port Said, 42521, Egypt

Email: ali_zoology_2010@yahoo.com

Received date: 2 December 2019, Accepted date: 21 January 2020, Online date: 31 January 2020

Copyright: (C) 2020 Ali Hussein Abu-Almaaty et al. This is an open-access article distributed under the terms of the Creative Commons Attribution License, which permits unrestricted use, distribution, and reproduction in any medium, provided the original author and source are credited.

\begin{abstract}
The objective of this research was focused on the ameliorative point of natural product extract (propolis) in liver's rat after exposure to two different doses of aluminum silicate (AIS). Sixty adult albino male rats (weighting: 100 to 120 gram) that were distributed into six groups equally as ten animals in each group for two months. The $1^{\text {st }}$ group was kept normally as healthy control one. The $2^{\text {nd }}$ group was taken propolis extract only $(200 \mathrm{ml} / \mathrm{kg})$ oral by stomach gavage tube during the experiment day after day. The $3^{\text {rd }}$ group was injected intra peritoneal (IP) by $5 \mathrm{mg} / \mathrm{kg}$ of AIS was considered as low dose, twice weekly. The $4^{\text {th }}$ group was received propolis extract as orally day after day and at the same time was injected with low dose $5 \mathrm{mg} / \mathrm{kg}$ of AIS, twice weekly. The $5^{\text {th }}$ group was exposed IP to $20 \mathrm{mg} / \mathrm{kg}$ of AIS as high dose (twice weekly). The $6^{\text {th }}$ group was given extract of propolis orally day after day and in the same time was injected with $20 \mathrm{mg} / \mathrm{kg}$ of AIS in twice weekly. At the end of experiment, pieces of liver were taken for biochemical assays as well as the whole liver for histopathological and histochemical examinations. The results showed in the biochemical activities of $3^{\text {rd }}$ and $5^{\text {th }}$ groups, highly significant decrease in glutathione reductase (GSH), glutathione S-transferase (GST) and superoxide dismutase (SOD) levels of rat hepatocytes (p-value $\leq \mathbf{0 . 0 1}$ ) while a marked increase in lactate dehydrogenase (LDH) and alkaline phosphatase (ALP) activities. Great histopathological changes were noticed in the architectural studied of liver sections and sever depletion was found in histochemical contents as carbohydrates and total protein. On the other hand, administration of propolis extract to both doses of AIS treated rats $\left(4^{\text {th }}\right.$ and $6^{\text {th }}$ groups $)$ showed a marked improvement in the biochemical activities as well as the histological background and moderately enhancement in the histochemical contents. In conclusion, there is a definitive cytotoxic effect of AIS in liver's rat that could be improved by the propolis extract due to its antioxidant properties. Propolis can take as a nutritional supplement and has a tremendous potential prophylactically to aluminum silicate toxicity.
\end{abstract}

Keywords: Aluminum silicate, Propolis, Liver, Biochemical assay, Histopathological and histochemical studies

\section{INTRODUCTION}

Aluminum silicate (AlS), is a chemical compound that is derived from aluminum oxide $\left(\mathrm{Al}_{2} \mathrm{O}_{3}\right)$ and silicon dioxide $\left.(\mathrm{SiO})_{2}\right)$ which may be hydrated or anhydrous, naturally occurring as minerals or synthetic. It has many uses that vary including many industrial applications like porcelain dishes, ceramic pots as various foods processing and other products as clays, glasses, stones and jewels. Besides, it has a significant toxic possible for humans that depended on its different chemical composition [1-3]. Nattrass et al. [4] were showed that mutagenic, carcinogenic and fibrogenic states cause the silica crystals. On the other hand, a natural product, propolis, is bee glue which was used as a supplement for improving the gastrointestinal functions, tumor inhibition, antiaging, antifatigue and regulate the physiological functions as well as considered as beneficial health effects [5]. Recently, propolis has discovered as the antiinflammatory and antioxidant impression that could defense effects induced by aluminum toxicity [1-3,6]. Actually, liver is considered as a mammalian pivotal organ because of it contains most accumulated toxic metals [7]. Many of researches were noticed the toxicity of aluminum compounds as aluminum silicate in different cases such as 
obstructive lung disease, cerebellum disorder as well as damage in chromosomes and some genes which responsible on growth levels $[1-3,8]$

\section{MATERIALS AND METHODS}

\section{Extraction of propolis}

The raw propolis was obtained from honey hives at the Faculty of Environmental Agricultural Science, Sinai University, North Sinai, Egypt. The extraction of propolis (PP.) was performed according to the procedure of Cunha et al. [9].

\section{Experimental animal}

Sixty adult male albino rats (Rattus norvegicus) weighting 100-120 g. The rats were obtained from the animal station in Helwan (Ministry of Health, Egypt). Animals were randomly divided into six groups ( $\mathrm{n}=10$ rats) and kept in plastic cages under proper ventilation and taken a balanced diet and water ad libitum for two months which are explained in Fig. 1 . The $1^{\text {st }}$ group was served as a normal control group. The $2^{\text {nd }}$ group was received propolis extract $(200 \mathrm{ml} / \mathrm{kg} \mathrm{b}$.wt) oral with a gavage tube (three times in a week). The $3^{\text {rd }}$ group was induced by $5 \mathrm{mg} / \mathrm{kg}$ of aluminum silicate as a low dose, twice in a week. The $4^{\text {th }}$ group was exposed to propolis plus aluminum silicate as doses in second and third groups. The $5^{\text {th }}$ group was intoxicated by $20 \mathrm{mg} / \mathrm{kg}$ of aluminum silicate as a high dose, twice weekly. The $6^{\text {th }}$ group was exposed to propolis plus aluminum silicate as doses in the second and fifth groups. After forty-eight hours from the last dose, the rats were euthanized and the liver was removed and divided into two parts (Fig. 2). The first part was used for biochemical analyses. The second part was harvested for histopathological and histochemical examinations.

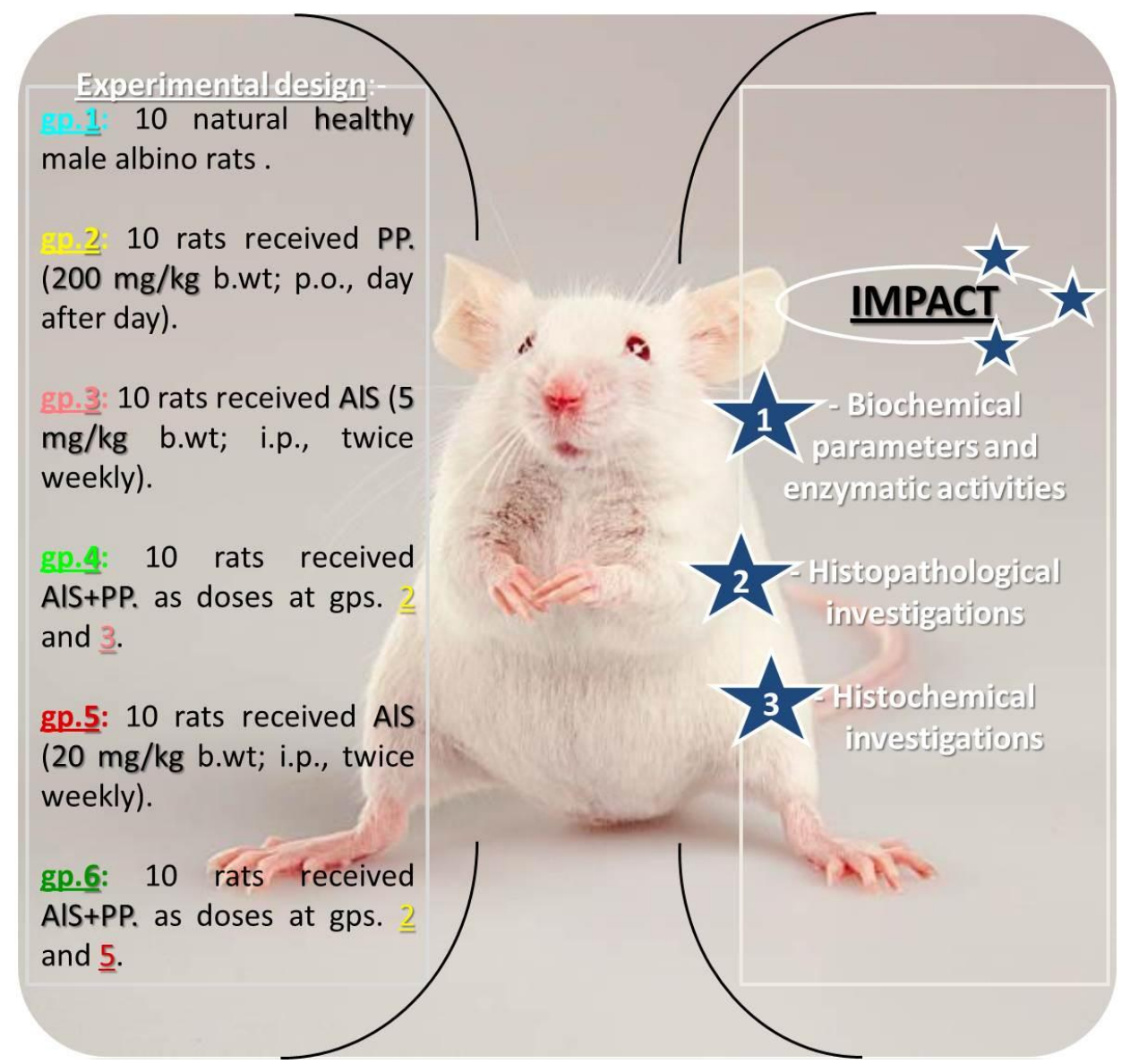

Fig. 1: A representation of experimental groups, design of work and the feedback of the present study 

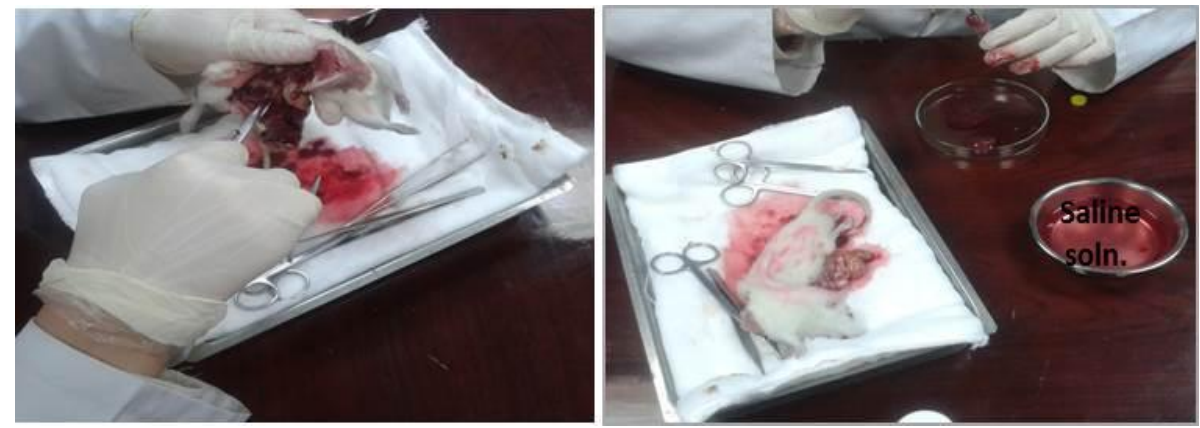

Fig. 2: Harvesting of the liver organ for different tests.

\section{Biochemical analyses}

The liver was isolated and then immersed in a saline solution $(0.9 \% \mathrm{NaCl})$ for washing the organ. The experimental organ was homogenate for obtaining the freshly innovative organ homogenate, then centrifuged. The supernatants were introduced to the spectrophotometer for measuring the biochemical analyses are including glutathione reductase (GSH) was adopted by Beutler [10], superoxide dismutase (SOD) was assayed by Nishikimi et al. [11] procedure and glutathione S-transferase (GST) as described by Habig et al. [12]. Besides, enzymatic activities are including lactate dehydrogenase (LDH) was assayed according to the procedure of Moss et al. [13] and alkaline phosphatase (ALP) was based on the enzymatic reaction of Bellfield and Goldberg [14].

\section{Histopathological studies}

The freshly collected liver organs were fixed in formalin solution (10\%) for forty-eight hours. The liver organs were transferred to dehydrate in ethanol, then xylene. The specimens were processed using paraffin wax and then were cut at $5 \mu \mathrm{m}$ in thickness by a microtome. For examination, the structure of liver specimens was stained by general stains (Hematoxylin and Eosin) and mounted with DPX [15]. For evaluation of the carbohydrate contents by many specific stains such as periodic acid Schiff stain (PAS) [16] and Alcian blue stain [17] as well as total protein contents by using the mercury bromophenol blue stain (BPB) [1820]. The stained experimental liver tissues were examined under a bright-field microscope (Leica, Germany) [21].

\section{Statistical analyses}

The biochemical analyses are presented as mean values $\pm \mathrm{SE}$ for animals experimented. The statistical significance is analyzed as follows: $* \mathrm{P} \geq 0.05, * * \mathrm{P} \leq 0.05$, and ${ }^{* * *} \mathrm{P} \leq 0.01$ for comparison to the control group.

\section{RESULTS}

Evaluation of the ability of propolis extract as an antioxidant factor for ameliorative on biochemical activities in liver tissues that induced by different doses of aluminum silicate

Briefly, the non-enzymatic parameters of GSH levels are decreased from $7.84 \pm 0.54 \mathrm{mg} / \mathrm{g}$ hepatocytes (healthy control) to $4.65 \pm 0.24 \mathrm{mg} / \mathrm{g}$ hepatocytes (AlS L.) and to $2.38 \pm 0.27 \mathrm{mg} / \mathrm{g}$ liver tissues (AlS H.). The measured level of SOD is downregulated from $33.78 \pm 0.95 \mathrm{U} / \mathrm{g}$ (healthy control) to $26.47 \pm 0.97 \mathrm{U} / \mathrm{g}$ (AlS L.) and $19.74 \pm 0.83 \mathrm{U} / \mathrm{g}$ (AlS H.). GST level is inhibited from $1.45 \pm 0.02$ (healthy control) to $0.89 \pm 0.03$ (AlS L.) and to $0.71 \pm 0.03$ (AlS H.) $\mu \mathrm{mol} / \mathrm{min} / \mathrm{g}$ fresh liver tissues. In the other hand, these toxicity effects were prophylactic by intake of propolis extract (200 $\mathrm{ml} \mathrm{kg}$ ) with AlS (low and high doses); the GSH increased to $6.07 \pm 0.36 \mathrm{mg} / \mathrm{g}$ liver tissues (AlS L.+PP.) and up-regulated to $3.47 \pm 0.33 \mathrm{mg} / \mathrm{g}$ hepatocytes (AlS H.+PP.), the level of SOD displayed increased to $30.25 \pm 0.68 \mathrm{U} / \mathrm{g}$ (AlS L.+PP.) and up-regulated to $23.60 \pm 0.95 \mathrm{U} / \mathrm{g}$ (AlS H.+PP.), as well as the GST level is increased to $1.04 \pm 0.04 \mu \mathrm{mol} / \mathrm{min} / \mathrm{g}$ (AlS L.+PP.) and marked increasing to $0.82 \pm 0.05 \mu \mathrm{mol} / \mathrm{min} / \mathrm{g}$ (AlS H.+PP.) (Fig. 3).

The enzymatic activities of LDH level are significantly up-regulated from $25.88 \pm 1.65$ (healthy control) to $32.39 \pm 1.40$ (AlS L.) and to $41.06 \pm 1.91$ (AIS H.) U/g fresh liver tissues while, the LDH level showed significant downregulating to $28.42 \pm 1.25$ (AlS L.+PP.) and markedly decreased to $37.01 \pm 1.85$ (AlS H.+PP.). The ALP level is raised from $257.34 \pm 14.21$ (healthy control) to $307.73 \pm 13.93$ (AlS L.) and to $386.27 \pm 13.77$ (AlS H.) U/g fresh liver tissues while, the ALP activity showed significant downregulating to $279.13 \pm 15.57$ (AlS L.+PP.) and markedly decreased to $348.55 \pm 14.25$ (AlS H.+PP.) (Fig. 3). 


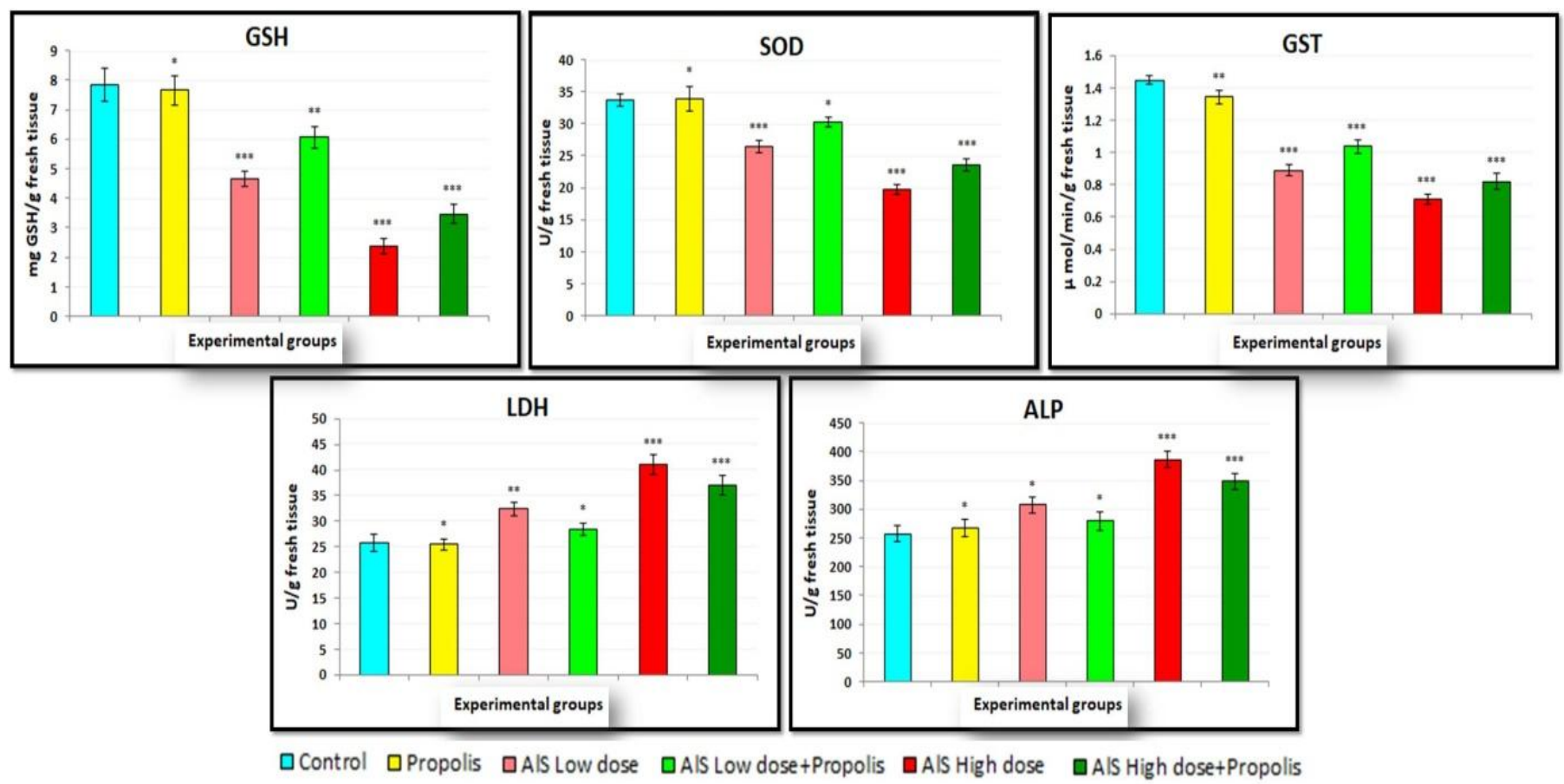

Fig. 3: Estimation of biochemical parameters for liver tissues of the different experimental groups. (The bars were represented mean values $\pm \mathrm{SE}, *$ : Non-significant, $* *$ : Significant and $* * *$ : Highly significant).

Necrosis stages were induced by two different doses of aluminum silicate and co-regulated by propolis extract as the natural product

The liver tissues were stained with $\mathrm{H} \& \mathrm{E}$ for various groups and investigated under a bright-field microscope to evaluate the cytotoxicity effects induced by AlS and the protective factor of propolis extract, as shown in Fig. 4. At the healthy control, hepatic cells polyhedral are rounded or oval disposed of one nucleus or sometimes with twice nucleated. The liver layers have appeared around the center vein. The zone between these liver strands contains many capillaries known as the hepatic sinusoids. The phagocytic immune cells have appeared in these sinusoids that named von Kupffer-Browicz cells (Fig. 4a). At propolis extract-treated animals, frequently architecture as the healthy ones (Fig. 4b). While the rats' liver is exposed to aluminum silicate $(5 \mathrm{mg} / \mathrm{kg})$ as a low dose had appeared sinusoids dilation. The dilated of central veins, and the endothelial cells are detachment and enlargement of Kupffer cells. Also, appeared of lymphatic infiltrations and corrosion was seen in the endothelial lining of the central portal vein (Fig. 4c). However, at propolis extract mixed with a low dose of aluminum silicate, the detected of liver cells as an advanced degree compared with the low treatment of aluminum silicate $(5 \mathrm{mg} / \mathrm{kg})$ induced rats. The hepatic cells showed intact and disappeared vacuolization show. More enhancement of hepatic tissues in the central vein, narrow liver sinusoids, regular single and binucleated of nuclei, some pyknocytes (Fig. 4d). The lost the standard structure of liver tissues. The lymphatic infiltrations and vacuolization have appeared in most of the hepatic cells. Changes in some Kupffer cells were seen. These cells recognized signs of necrosis as karyorrhexis, karyolysis and pyknosis stages were showed at the high dose of aluminum silicate $(20 \mathrm{mg} / \mathrm{kg}$ ) intoxicated rats (Fig. 4e). However, by propolis extract addition to aluminum silicate (high dose), the hepatic cells showed mild enhance that compared with the high dose of aluminum silicate $(20 \mathrm{mg} / \mathrm{kg})$ induced animals. No seen mend in the Kupffer cells that still increased in their activity and size (Fig. 4f). 


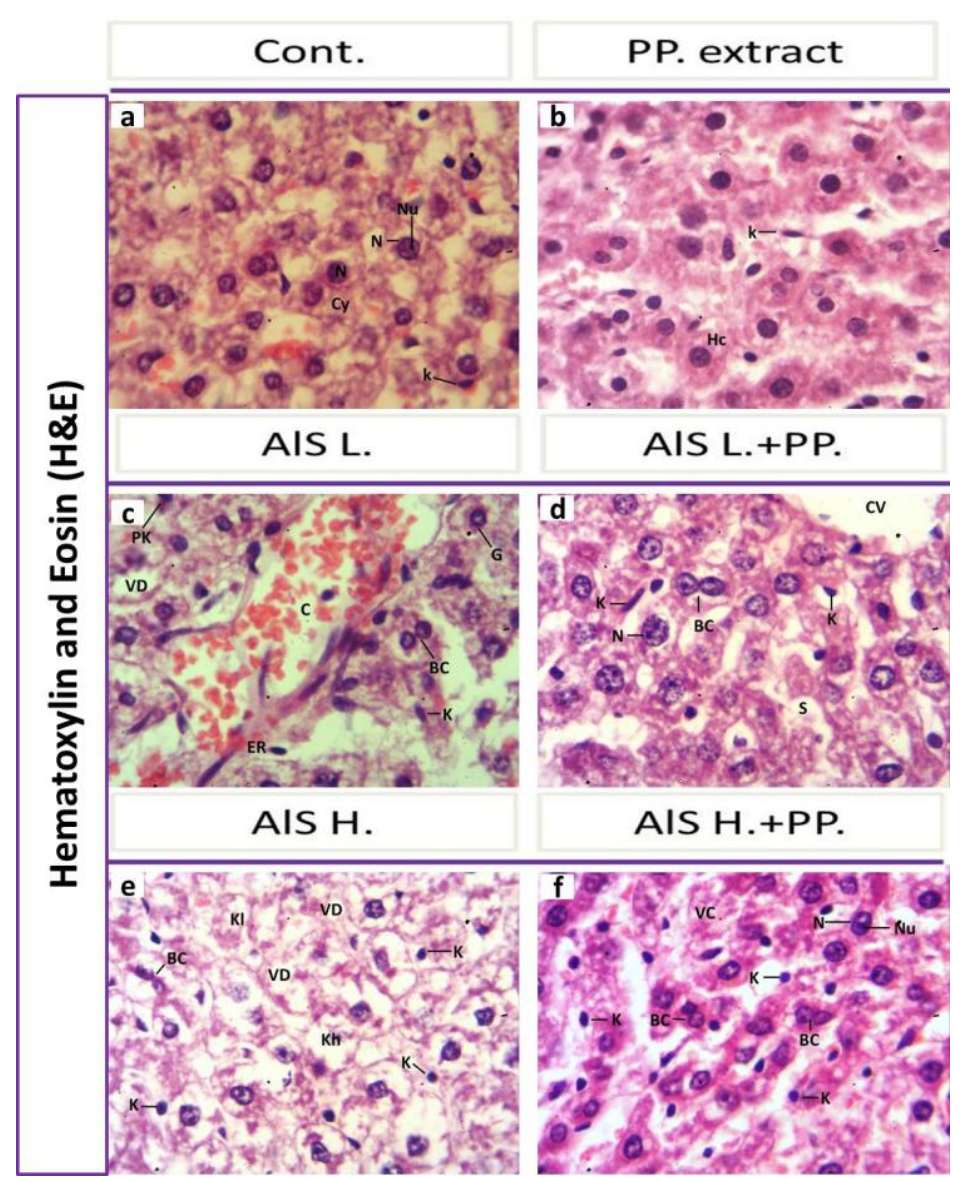

Fig. 4: a-f) Section of hepatic tissues stained with H\&E (magnification power, $400 \mathrm{x}$ ). liver sections show the nuclei (N), nucleoli $(\mathrm{Nu})$, Kupffer cells $(\mathrm{K})$, cytoplasm $(\mathrm{Cy})$, hepatocytes $(\mathrm{Hc})$, congestion of blood vessels $(\mathrm{C})$, erosion of the endothelial which line the central hepatic vein (ER), binucleated cells (BC), pyknotic cells (Pk) of hepatocytes, vacuolar degeneration (VD), hepatic sinusoids (S) and obvious vacuolar degeneration (VD) of hepatic cells.: a) Control liver tissues explained the normal agriculture of hepatocytes. b) Rats received propolis extract (PP.) is the same as that of healthy control. c) Rats intoxicated to aluminum silicate as low dose (recognized a pyknotic cell that is pre-stage of necrosis. d) Animals exposed to AlS L. with propolis extract (AlS L.+PP.) demonstrated an enhancement in the liver tissues. e) Rats induced by high aluminum silicate dose (AlS H.) seen the appearance of swollen of Kupffer cells and necrosis stages. f) Rats exposed to aluminum silicate as a high dose with propolis extract (AlS H.+PP.) showed signs of mild improvement in liver tissues.

\footnotetext{
Downregulation of glycogen and carbohydrate contents induced by different doses of aluminum silicate and ameliorative by propolis extract co-administration

To investigate the contents of glycogen and much-polysaccharide in the hepatic tissues, two specific strains were performed. Briefly, periodic acid Schiff (PAS) reaction and Alcian blue were prepared. In the case of normal and propolis extract exposed rats, liver tissues detected homogeneously distribution of PAS-positive reaction and Alcian blue (Fig. 5a, b, g, and h). While the acid mucopolysaccharides contents were down-regulated in the hepatocytes that exposed to aluminum silicate as the low dose at compared to the control rats (Fig. 5c and i). However, the hepatocytes in which exposure to a high dose of aluminum silicate was apparent than the centrally located ones (Fig. 5e, 1). Surprisingly, the co-supplement of propolis extract enhanced glycogen contents as examination with PAS reaction (Fig. 5d and f) and alcian blue (Fig. 5k and m). In summary, liver tissues were lost glycogen contents induced by AlS and improved by propolis extract co-administration.
} 

Cont.
PP. extract
AIS L.
AIS L.+PP.
AlS $\mathrm{H}$.
AlS H.+PP.
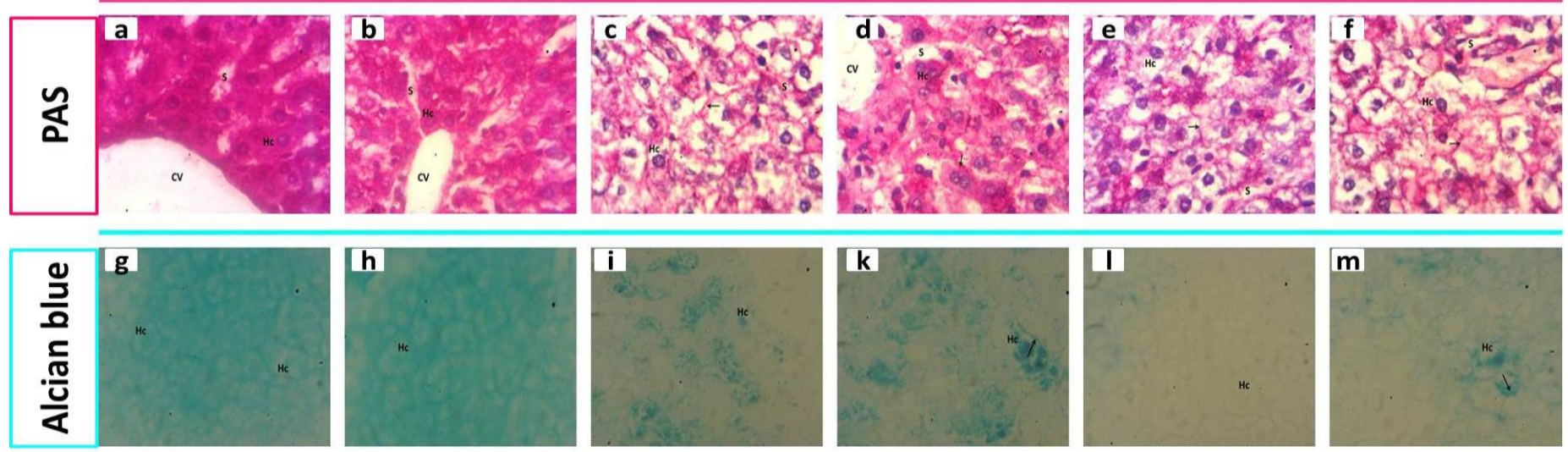

Fig. 5: a-f) Sections of hepatic tissues stained with PAS reaction and g-m) Liver tissues stained with Alcian blue reaction (magnification power, 400x). Liver sections notice the hepatocytes (Hc) which around the central vein (CV), blood sinusoidal space (S) and glycogen flight (arrow).: a, g) Tissues from control animals have recognized a magenta color for PAS reaction and a bluish color for Alcian blue in the ground cytoplasm of hepatic strands. b, h) Rats received propolis extract (PP.) showed similar to control healthy rats. c, i) Significantly diminished glycogen contents in case of rats which intoxicated to AlS L. d, k) Rats induced by aluminum silicate (low dose) plus propolis extract (AlS L. +PP.) demonstrated enhancement of carbohydrate contents in liver tissues. e, l) Highly marked decrease of carbohydrate contents in case of AlS H. dose-treated animals. f, m) AlS H.+PP. Exposed animals showed a sign a few ameliorative of carbohydrate contents in liver tissues.

\section{Reduction of total protein contents in liver tissues of rats intoxicated by different doses of aluminum silicate and improvement by propolis extract co-administration}

To evaluate the total protein contents in hepatic tissues of rat, mercury bromophenol blue (BPB) was performed. Briefly, both control and propolis extract of rats represented intensive in bluish color for total protein inclusions were showed in Fig $6 \mathrm{a}$ and $\mathrm{b}$. While rats intoxicated to aluminum silicate (low dose) were recognized diminish in this reaction (Fig. 6c). Low aluminum silicate dose plus propolis extract exposed animals appeared to improve in total protein contents in most cells of the liver organ (Fig. 6d). Protein inclusions were diminished after intoxicated to aluminum silicate as a high dose (Fig. 6e). On the other hand, rats are induced by high aluminum silicate dose plus propolis extract were seen the mild improvement of the protein inclusions in the hepatic cells (Fig. 6f).

Cont.

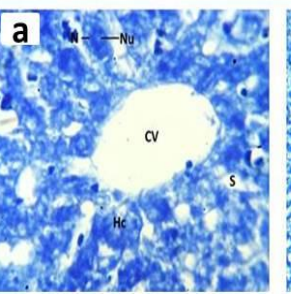

PP. extract

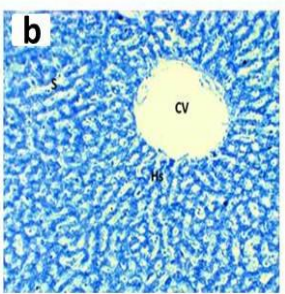

AIS L.

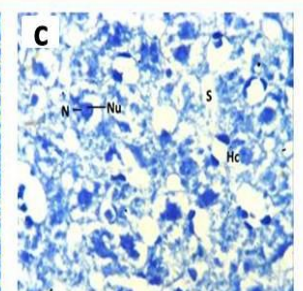

AlS L.+PP.

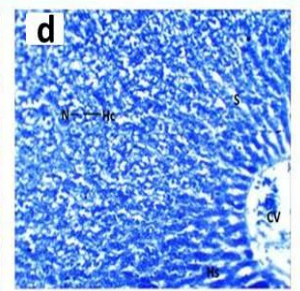

AlS H.

AIS H.+PP.

Fig. 6: a-f) Sections of liver tissues stained with mercury bromophenol blue (BPB) for detecting total protein contents (magnification power, 400x). The liver section displays the hepatic central vein $(\mathrm{CV})$, nuclei $(\mathrm{N})$, nucleoli $(\mathrm{Nu})$, hepatocytes (Hc) are arranged in the hepatic strands (Hs) and hepatic sinusoidal space (S).: a) Control healthy liver demonstrated bluish color of total protein in the hepatic strands. b) Rats received propolis extract (PP.) is similar to control. c) Rats intoxicated to AlS L. seen diminished in this reaction. d) AlS L.+PP. the observed improvement in the blue color of total protein inclusions in hepatic strands by this reaction. e) The decreased blue color of this reaction in hepatic tissues after intoxicated by AlS H. f) Some ameliorative of total protein inclusions appeared in liver cells after induced by AlS H.+PP.

\section{DISCUSSION}

In the last decades, human populations are continuously exposing to aluminum silicate (AlS) through various sources in our life during the uses of the soil, clay, glasses, ceramic cooking, and porcelain pots utensils. Many publications referred to the cytotoxicity of aluminum derivatives such as aluminum chloride, aluminum hydroxide, aluminum phosphate, aluminum oxide, aluminum lactate and aluminum silicate [1-3,22-26]. This study was focused on clearly effect the different doses of aluminum silicate in the liver tissues and propolis extract co-administration.

Aluminum silicate (AlS) was promoted oxidative stress, contributed to the development of several pathological conditions and altered intracellular matrix involving oxidative stress that is driven by an imbalance between oxidant and antioxidant defenses 
due to its long accumulation in various tissues. Our data of GSH and GST activities demonstrated a downregulate in the liver tissue homogenates in rats injected by aluminum silicate (low and high doses), that in accordance with the authors in recent publication [27] that studied the oxidative toxic effect induced by aluminum element on liver, kidney, spleen, lung, and brain cells. The intracellular mitochondria role is protecting the cell from lipid peroxidation by the role of GSH as an antioxidant function [28]. So, when organs were exposed to aluminum silicate, it caused accumulation of free radicals possible to membrane fragility subsequently of the cell and depletion of the GSH level in many tissues that lead to cause the mitochondria product complex-I which exposed to free radical attack in a velvet glove. The present results indicated a depletion in the SOD level of rat liver tissue homogenates and was confirmed by using the mercury bromophenol blue histochemical stain for estimation of inhibition protein contents which stored in the used experimental organs where the SOD is an indicator to the intracellular protein contents, this finding is agreement with other many studies when exposed to other aluminum compound s to experimental animals $[27,29,30]$ that leading to decrease catalase action, accumulate of $\mathrm{H}_{2} \mathrm{O}_{2}$ in the several tissues and depletion of SOD caused tissue damage which associated with the physiological functions to produce dysfunctions and disorders in several systems.

This study was also examined with LDH and ALP enzymatic parameters contents in rat liver tissue homogenates induced by AlS. It was showed a marked high release of LDH and ALP. After induction of AS low dose, LDH and ALP enzymes increased the expression and elevated more by a high dose of AlS exposure, these results are in agreement with other findings [31,32]. They explained the increase of enzymatic parameters in the several tissues induced by other aluminum compounds as aluminum chloride, aluminum lactate and aluminum sulfate. In our study, by treating the animal models with the natural product as propolis extract $(200 \mathrm{mg} / \mathrm{kg}$ b.wt of rat $)$, it is found that an amelioration response of the cellular antioxidant after both low and high doses of AlS induction. This improvement revealed the decrease of free radicals in several cells and enhancement of levels of antioxidant parameters as GSH, SOD and GST and enzymatic activities as ALP and LDH contents in the tested experimental organ.

In the view of the histopathological investigation, the rat hepatocytes which intoxicated to aluminum silicate (low and high doses) that examined appearance in the hepatic central veins were dilated, sinusoidal dilation and activated Kupffer cells were found as evidenced by enlargement in size and detachment of the endothelial cells. Lymphatic infiltrations were also seen in the portal space. Also, there were enlarged in the hepatic tissues with their nuclei, cytoplasmic vacuolization, and showed apparent of karyorrhexis, karyolysis and pyknosis stages of necrosis were recorded. These our histopathological investigations are agreement with other studies that exposed aluminum element to experimental animals [33-36].

By histochemical examinations, there is an observation for serious depletion in contents of carbohydrate and total protein which were stored in liver tissues by using the histochemical specific stains. On the other means, a decreased in the glycogen contents which stored in the liver cells that induced by both low and high aluminum silicate, where the aluminum element has the ability to bond with several peptides, glycoproteins as well as carbohydrates like oxalate, isocitrate, malate, tartrate, and succinate. This result product forms of aluminum lead to sign up-regulation of absorption values, mitochondrial damage imbalance carbohydrate contents, biosynthetic reactions, lipid homeostasis and amino acid metabolism [37-39], this our findings are agreement with other studies $[40,41]$. In our study, using many stains for carbohydrate characterization showing there was reducing of marked colors indicated the depletion of carbohydrate contents. Another investigation by mercury bromophenol blue stain for total protein contents in liver tissue after induction of aluminum silicate, there was a limiting of the marked color of bromophenol blue indicated that downregulation of protein contents in the hepatocytes as agreed with other authors [41,42].

On the other hand, the propolis is considered the most interesting of many authors due to its powerful antioxidant activity as the natural product by suppressing the oxidative damage induced by the surrounding environment as a protective effect. Recently, propolis uptake is usually supplied with food and using as a supplemented therapy for malignant cells as a treatment or preventable [1-3,43]. In another point of view, the propolis as a treatment after induction of aluminum chloride in rats and found it is useful in another organ of an animal model like kidney and so propolis extract has many ameliorated effects when uptake daily regularly [44]. Our study was also aimed to determine the curative effect of propolis extract in the presence of aluminum silicate exposure.

\section{CONCLUSION}

Aluminum silicate induces distortion on the liver tissues. Antioxidant properties of propolis extract might markedly an ameliorative factor in liver organ damage induced by aluminum silicate toxicity. Future studies are needed for confirmation of the importance of propolis extract and bee products as a nutritional supplement for pharmaceutical and medical applications.

\section{REFERENCES}

[1] Abd El-Aziz, Y.M., A.H. Abu-Almaaty, N.A. Omar, A.M. Abdeen and M.M. Zakaria, 2019. Evaluation of protective effects of propolis against aluminium silicate toxicity in rats. Genetika, 51(1): 299-312.

[2] Omar, N.A., A.H. Abu-Almaaty, Y.M. Abd El-Aziz, A.M. Abdeen, FEZ.A. Mohamed, M.M.M. Hashem and S. Hammad, 2019. Impacts of Egyptian propolis extract on rat cerebellum intoxicated by aluminum silicate: histopathological studies. Environ. Sci. Pollut. Res. Int., 26(21): 22061-22068.

[3] Abu-Almaaty, A.H., Y.M. Abd El-Aziz, N.A. Omar, A.M. Abdeen, 2019. Estimation of the prophylactic effect of the Egyptian propolis extract against aluminum silicate toxicity on some organs of albino rats: growth performance and histochemical studies. Egypt. J. Hosp. Med., 76(7): 4564-4569. 
Citation: Ali Hussein Abu-Almaaty et al 2020., Prophylactic impact of Egyptian propolis on rat liver exposed to aluminum silicate toxicity: biochemical and histo pathological studies. Advances in Environmental Biology, 14(1): 56-64. DOI:10.22587/aeb.2020.14.1.9

[4] Nattrass, C., C.J. Horwell, D.E. Damby, D. Brown and V. Stone, 2017. The effect of aluminium and sodium impurities on the in vitro toxicity and pro-inflammatory potential of cristobalite. Environ. Res., 159: 164-175.

[5] Yousef, M.I. and A.F. Salama, 2009. Propolis protection from reproductive toxicity caused by aluminium chloride in male rats. Food Chem. Toxicol., 47(6): 1168-1175.

[6] Mahmoud, M.E. and S.S. Elsoadaa, 2013. Protective effect of ascorbic acid, biopropolis and royal jelly against aluminum toxicity in rats. J. Natural Sci. Res., 3(1): 102-112.

[7] Kurutaş, E.B., A. Sahan and T. Altun, 2009. Oxidative stress biomarkers in liver and gill tissues of spotted barb (Capoeta Barroisi Lortet, 1894) living in Ceyhan river, Adana-Turkey. Turk. J. Biol., 33(4): 275-282.

[8] Elserougy, S., H. Mahdy-Abdallah, S.F. Hafez and S. Beshir, 2015: Impact of aluminum exposure on lung. Toxicol. ind. health, 31(1): 73-78.

[9] Cunha, I., A.C. Sawaya, F.M. Caetano, M.T. Shimizu, M.C. Marcucci and F.T. Drezza, 2004. Factors that influence the yield and composition of Brazilian propolis extracts. J. Brazilian Chem. Soc., 15(6): 964-70.

[10] Beutler, E., 1982. Red cell metabolism, a manual of biochemical methods. New York: Grune \& Stratton., (Ed.), 89-137.

[11] Nishikimi, M., N. Roa and K. Yagi, 1972. The occurrence of superoxide anion in the reaction of reduced phenazine methosulphate and molecular oxygen. Biochem. Biophys. Res. Commun., 46: 849-859.

[12] Habig, W.H., M.J. Pabst and W.B. Jakoboy, 1974. Glutathion S-transferase the first enzyme step in mercapturic acid formation. J. Biol. Chem., 249: 7130-7139.

[13] Moss, D.W., A.R. Hendersen and J.R. Kachmar, 1986. Enzyme. In: Textbook of clinical chemistry. Tietz, N. W. (Ed.), W. B. Saunders, Phila., 619-663.

[14] Belefield, A. and M.D. Goldberg, 1971. Colorimetric determination of acid phosphatase activity. Enzyme, 12(5): 561-568.

[15] Fischer, A.H., K.A. Jacobson, J. Rose and R. Zeller, 2008. Hematoxylin and eosin staining of tissue and cell sections. Cold Spring Harbor Protocols, doi: 10.1101/pdb.prot4986.

[16] Clayden, E.C., 1971. Practical section cutting and staining.

[17] Crookham, J. and R. Dapson, 1991. Hazardous chemicals in the histopathology laboratory, $2^{\text {nd }}$ Ed., Anatech. Ltd.

[18] Ali, D., N. Badr El-Din and R. Abou-El-magd, 2015. Antioxidant and hepatoprotective activities of grape seeds and skin against Ehrlich solid tumor induced oxidative stress in mice. Egypt J. Basic Appl. Sci., 2: 98-109.

[19] Mazia, D., P.A. Brewer and M. Alfert, 1953. The cytochemical staining and measurement of protein with mercuric bromphenol blue. Biol. Bull., 104: 57-67.

[20] Shati, A.A., 2014. Ameliorative effect of vitamin E on potassium dichromate-induced hepatotoxicity in rats. J. King Saud University- Science., 26: 181-189.

[21] Bancroft, J.D. and M. Gamble, 2008. Theory and practice of histological techniques. In: Churchill Livingstone. Elsevier, China.

[22] Kumar, V. and K.D. Gill, 2009. Aluminium neurotoxicity: neurobehavioural and oxidative aspects. Arch. Toxicol., 83(11): 965-978.

[23] Kamal, I. and H. Kamal, 2013. Effects of aluminum on rat cerebellar cortex and the possible protective role of Nigella sativa: a light and electron microscopic study. Egypt. J. Histol., 36(4): 979-990.

[24] Hassanin, L.A., A.M., Salama, E.A. Essa and M.A. El-Moniem, 2017. Potential role of some nuTrace.uticals in neurotoxicity induced by aluminum oxide in experimental animal model. Int. J. Adv. Res. Biol. Sci., 4(11): $72-89$.

[25] Mrad, I., M. Sakly and S. Amara, 2017. Aluminum oxide nanoparticles induced cognitive def cits and oxidative stress in frontal cortex and cerebellum of rat. Adv. J. Toxicol. Curr. Res., 1(1): 7-14.

[26] Wang, X., Y.Xi, X. Zeng, H. Zhao, J. Cao and W. Jiang, 2018. Effects of chlorogenic acid against aluminium neurotoxicity in ICR mice through chelation and antioxidant actions. J. Funct. Foods, 40: 365-376.

[27] Nathiya, S. and A. Nandhini, 2017. Evaluation of antioxidant effect of Salacia oblonga against aluminum chloride induced visceral toxicity in albino rats. Int. J. Basic Clin. Pharm., 3(2): 315-319.

[28] Meister, A., 1991. Glutathione deficiency produced by inhibition of its synthesis, and its reversal; applications in research and therapy. Pharmacol. Ther., 51: 155-194.

[29] Sanchez-Fidalgo, S., 2013. Dietary unsaponifiable fraction from extra virgin olive oil supplementation attenuates acute ulcerative colitis in mice. Eur. J. Pharm. Sci., 48(3): 572-581.

[30] Ghorbel, I., M. Chaâbane, O. Boudawara, N.G. Kamoun, T. Boudawara and N. Zeghal, 2016. Dietary unsaponifiable fraction of extra virgin olive oil supplementation attenuates lung injury and DNA damage of rats co-exposed to aluminum and acrylamide. Environ. Sci. Pollut. Res., 23(19): 19397-19408.

[31] Hamed, M.A., 2006. Effect of vitamin C on serum protein profile in mice after aluminum sulphate intoxication. Pol. J. Food Nutr. Sci., 15/56(2): 339-348.

[32] Al-Hashem, F., 2009. Camel's milk protects against aluminum chloride-induced toxicity in the liver and kidney of white albino rats. Am. J. Biochem. Biotechnol., 5(3): 98-109.

[33] Al-Eisa, R.A. and H.A. Al-Nahari, 2017. The attenuating effect of royal jelly on hormonal parameters in aluminum chloride $\left(\mathrm{AlCl}_{3}\right)$ intoxicated rats. Int. J. Pharm. Res. Allied Sci., 6(2): 70-85.

[34] Cheng, D., X. Zhang, L. Xu, X. Li, L. Hou, and C. Wang, 2017. Protective and prophylactic effects of chlorogenic acid on aluminum-induced acute hepatotoxicity and hematotoxicity in mice. Chem. Biol. Interact., 273: 125-132.

[35] Yu, L., Q. Zhai, R. Yin, P. Li, F. Tian, X. Liu, J. Zhao, J. Gong, H. Zhang and W. Chen, 2017. Lactobacillus plantarum CCFM639 alleviate trace. Element imbalance-related oxidative stress in liver and kidney of chronic aluminum exposure mice. Biol. Trace. Elem. Res., 176: 342-349. 
[36] Nour-Eldein, N.H., E.A. Hassanin and W.M. El-Sayed, 2018. Mitigation of acute aluminum toxicity by sodium selenite and $\mathrm{N}$-acetylcysteine in adult male rats. Biol. Trace. Elem. Res., 183: 128-137.

[37] Berthon, G., 2002. Aluminium speciation in relation to aluminium bioavailability, metabolism and toxicity. Coord. Chem. Rev., 228: 319-341.

[38] Mailloux, R.J. and V.D. Appanna, 2007. Aluminum toxicity triggers the nuclear translocation of HIF-1alpha and promotes anaerobiosis in hepatocytes, Toxicol. In Vitro, (21): 16-24.

[39] Mailloux, R.J., S. Puiseux-Dao and V.D. Appanna, 2009. Alpha-ketoglutarate abrogates the nuclear localization of HIF1alpha in aluminum-exposed hepatocytes, Biochimie., (91): 408-415.

[40] Dua, R., V. Kumar, A. Sunkaria and K.D. Gill, 2010. Altered glucose homeostasis in response to aluminium phosphide induced cellular oxygen deficit in rat. Indian J. Exp. Biol., 48: 722-730.

[41] Al-Amoudi, W.M. 2017. Effect of grapefruit juice on aluminum-induced hepatotoxicity in albino rats: histological, ultrastructural and histochemical assessment. Adv. Biosci. Biotechnol., (8): 463-477.

[42] Ogueche, P.N., C.E. Ugwu, D.N. Ezejindu, M. Omeje, C.C. Dike, C.O. Okonkwo, H.C.C. Maduka, and O. Obidoa, 2014. Aluminum intoxication induced biochemical and histopathological alterations in male Wistar albino rats hepatocytes. J. Natural Sci. Res., (4): 6-12.

[43] Bakour, M., N.S. Al-Waili, N. El Menyiy, H. Imtara, A.C. Figuira, T. Al-Waili and B. Lyoussi, 2017. Antioxidant activity and protective effect of bee bread (honey and pollen) in aluminum-induced anemia, elevation of inflammatory makers and hepato-renal toxicity. J. Food Sci. Technol., 54(13): 4205-4212.

[44] EL-kenawy, A., H. Osman, H. Eldin and M.H. Daghestani, 2014. Role of propolis (bee glue) in improving histopathological changes of the kidney of rat treated with aluminum chloride. Environ. Toxicol., 29(9): 1000-1010. 